\title{
Peak Level of Pain while uprighting Molars with Tri-helical Uprighting Spring
}

\author{
Dr Rajiv Yadav,' Dr Dennis C Lim² \\ 'Assistant Professor, Department of Dentistry - Orthodontics PG Section \\ Institute of Medicine, Tribhuvan University, Kathmandu, Nepal \\ ${ }^{2}$ Professor, Department of Orthodontics, University of the East, Manila, Philippines
} Correspondence: Dr Rajiv Yadav; Email: drrajivresearch@gmail.com

\section{ABSTRACT}

Introduction: Orthodontic treatment has clear positive effects on a patient's physiological, functional, esthetic, psychological, and social health. However the most common and problematic sequel of orthodontic treatment is pain and discomfort.

Objectives: To find out exact time of peak level of pain while uprighting molars for a week time with loop uprighting mechanics and weather the pain was associated with intake of pain medication.

Materials \& Method: A cross-sectional analytical study was performed on finally selected thirty orthodontic patients with uprighting molars with age range of 10-40 years from of the Department of Orthodontics, University of the East, Philippines. Digitest Electricpulp tester was used to calibrate subjects with similar pain threshold level. An optimal molar uprighting force of 100 grams was employed with a customized tri-helical molar uprighting springs made with 0.016 X0.022" stainless steel archwire. Measurement was done using tension gauge. Simultaneously 12 thermometer pain scale and 6 questionnaires forms were given to the subjects which were to be completed within 7 days based on their pain perception. The data were analyzed with Wilcoxon rank sum test, Chi-square test.

Result: Maximum pain was felt on day-1 during evening at 9:40 pm, which was strongly associated with intake of pain medication on day-1 with gradual decrease over a period of week.

Conclusion: There is a great need of precautionary measures like pain medication to avoid disturbance from daily activities of patients undergoing orthodontic treatment.

Keywords: molar uprighting, peak pain, tri-helical uprighting spring

\section{INTRODUCTION}

Pain is a common occurrence during the orthodontic tooth movement, especially immediately following the archwire placement or adjustment. It is a complex phenomenon involving multiple variants and is influenced by factors such as age, gender, individual pain threshold and amount of force applied. '

Discomfort is expressed as unpleasant tactile sensations, feeling of constraint in the oral cavity, stretching of the soft tissues, pressure on the mucosa, displacement of the tongue, soreness of teeth and pain. $^{2}$

Orthodontic treatment has clear positive effects on a patient's physiological, functional, esthetic, psychological, and social health. However, it is also associated with complications such as root resorption, caries formation, gingival/periodontal problems, allergic stomatitis, systemic metal accumulation, and iatrogenic damage during bracket debonding and bonding removal. The most common and problematic sequel of orthodontic treatment is pain and discomfort. ${ }^{3}$

Fixed orthodontic appliances include a wide variety of archwires as means of delivering forces upon teeth. Light and continuous force is desirable to achieve physiologic tooth movement with minimum pathological effect on the teeth and surrounding structures. ${ }^{4}$

Studies have shown that pain generally increases during the first 24 hours after the appliance has been fitted and then gradually reduces over the following week. This cycle is often repeated as the teeth align and progressively stiffer archwires are placed, which can affect routine day-to-day activities, such as eating and sleeping; and often requires the consumption of oral analgesia. ${ }^{5}$ 
Pain is a subjective response, which shows large individual variations. It is dependent upon factors such as age, gender, individual pain threshold, magnitude of force applied, present emotional state and stress, cultural differences, and previous pain experiences. Surveys regarding the percentage of patients experiencing pain have reported values ranging from $70 \%$ (Caucasian) to $95 \%$ (Asian populations). A report has even stated that $8 \%$ of a study population discontinued treatment because of pain. Surprisingly, this important area in clinical practice as well as research are ignored, as evidenced by the scarcity of publications. ${ }^{6}$

Although everyone has experienced pain and described it as sharp, burning, aching, cramping, dull, or throbbing sensations; the actual pain experience varies greatly as a result of human emotions. The expression of these emotions may be the reason why the word pain has not been defined in a manner agreeable to all. This study will be beneficial by providing the awareness as which part of the day will exhibit maximum pain after loading the tri-helical uprighting spring; so that the patient can take precautionary measures in advance. Most of the studies state that orthodontic pain is at peak on first day of loading the orthodontic appliance, which is a whole day long span of time. This unexplained fact evolved our aim of the study to locate the particular point of time at which the pain is at its peak level, thus the study was purposed.

The aim of the study was to find out peak level of pain while uprighting the molars using tri-helical uprighting spring from Day-1 to Day-7 and also to explore whether the pain was associated with the intake of pain medication over a period of week.

\section{MATERIALS AND METHOD}

The present cross-sectional analytical study involved the subjects with the age ranging from 10-40 years. Ethical clearance was obtained from University Graduate School Ethical Board. Study was conducted after receiving the written consent from the participants.

A total of 71 patients with mesially tilted molars who needed molars to be uprighted as a part of orthodontic treatment were selected as sampling frame from the Orthodontic Department, University of the East, Manila, Philippines. Since pain threshold is dependent on multiple factors; Digitest electric pulp tester (model 628D, USA) (Figure 1) was used to calibrate the level of pain threshold.

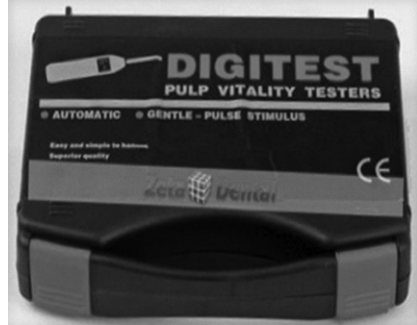

Figure 1: Electric Pulp tester

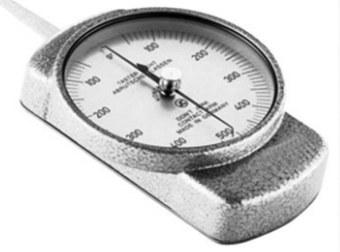

Figure 2: Tension gauge
Standardization of 100 grams of force by the uprighting spring on the molars

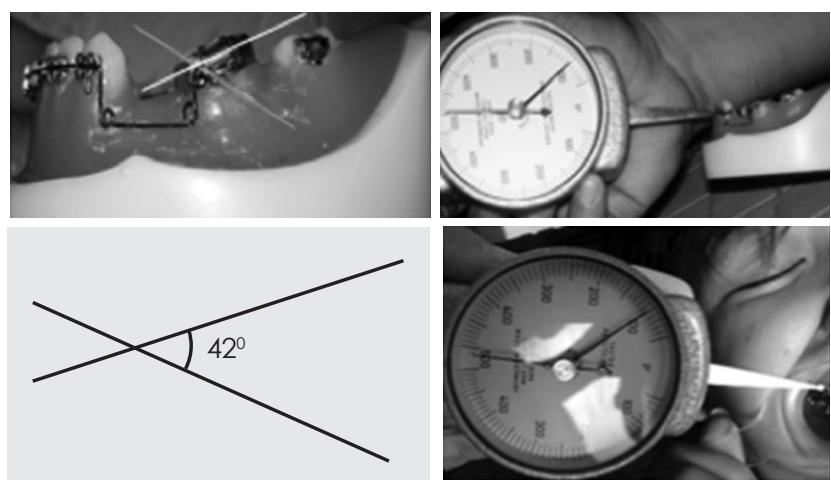

Figure 3: Standardization of optimal uprighting force of 100 grams with tension gauge (A derived angle of $42^{\circ}$ formed between the terminal tip back bend of uprighting spring and slot of molar band when loaded gives 100 grams of optimal force for molar uprighting.)

71 patients with uprighting springs were screened and grouped based on the high or low pain threshold. Among them 30 mesially tilted molars with similar pain threshold were selected as a final sample size.

A customized tri-helical molar uprighting springs made with $0.016 \times 0.022 "$ stainless steel archwire whose terminal tip back bend was inserted in 0.018" slot edgewise molar band for uprighting. An optimal orthodontic force of 100 grams for tri-rooted molar uprighting was employed based on the standardized measurements done by tension gauge (Forestadent, Germany) (Figure 2). An angle of $45^{\circ}$ formed between the terminal end tip back bend and slot of molar band was derived. This derived $45^{\circ}$ angle provides exactly 100 grams of required optimal force (Figure 3).

Immediately after loading of uprighting spring, patients were given instructions and handed over thermometer pain scale (Figure 4) to grade the pain level eight hourly i.e. three times a day at $6^{\text {th }}, 18^{\text {th }}, 24^{\text {th }}, 32^{\text {nd }}, 43^{\text {rd }}, 49^{\text {th }}, 56^{\text {th }}$, $67^{\text {th }}, 73^{\text {rd }}, 80^{\text {th }}$ hours, $5^{\text {th }}$ and $7^{\text {th }}$ day. The questionnaire (Figure 4) were also provided simultaneously on same day and were asked to mark once daily on $1^{\text {st }}, 2^{\text {nd }}, 3^{\text {rd }}$ $5^{\text {th }}$ and $7^{\text {th }}$ days. These readings were gathered and analyzed using Wilcoxon rank-sum test, Chi Square test. 


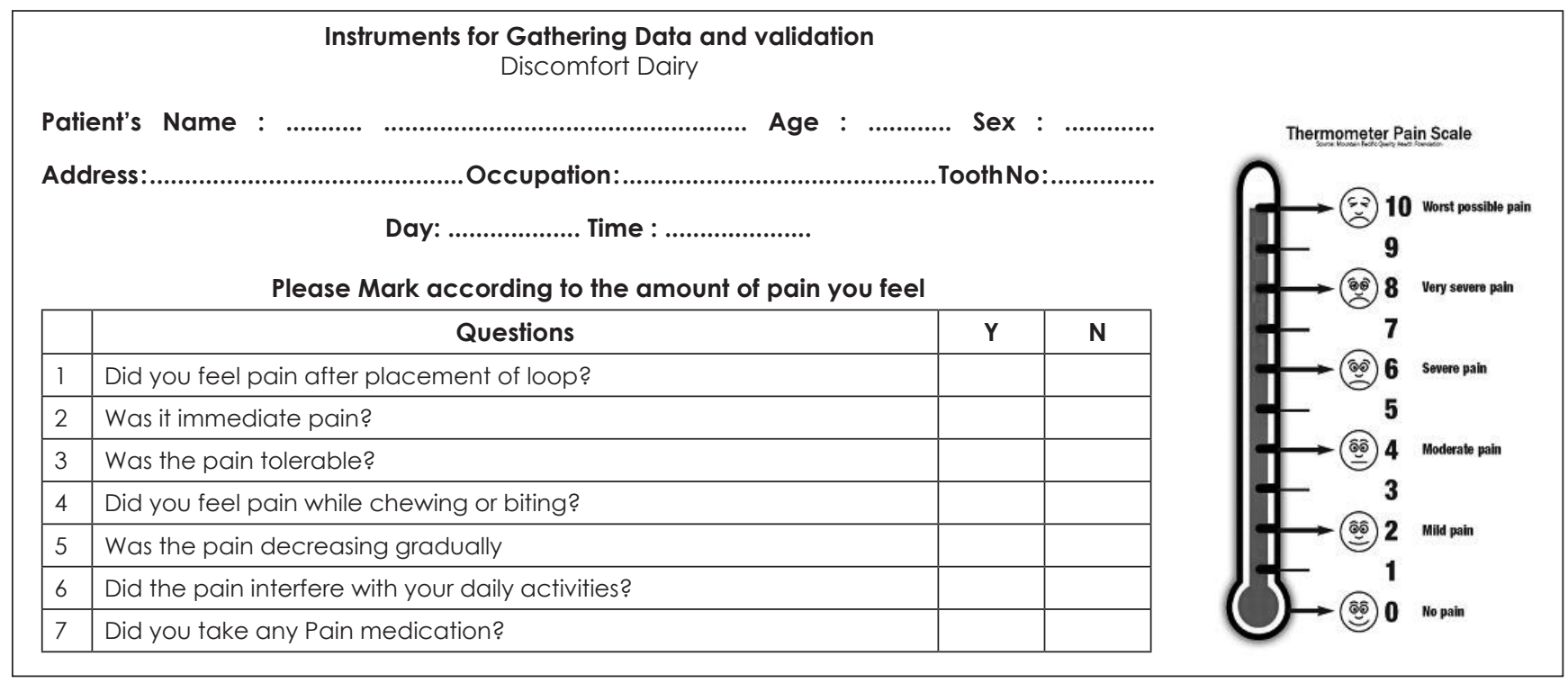

Figure 4: Questionnaire and Thermometer Pain Scale

\section{RESULT}

Maximum level of pain recorded was on day-1 during the evening at 9:40 pm. Maximum intake of pain medication was on day-1 due to most severe pain. There was a gradual decrease in level of pain over a period of a week. The response in the questionnaire supported the result of the thermometer pain scale (Table 1-4).

Table 1: Overall mean pain score from day-1 to day-7

\begin{tabular}{|l|c|c|c|c|c|c|c|c|c|c|c|c|}
\hline \multirow{2}{*}{ Time } & Day-1 & \multicolumn{3}{|c|}{ Day-2 } & \multicolumn{3}{c|}{ Day-3 } & \multicolumn{3}{c|}{ Day-4 } & Day-5 & Day-7 \\
\cline { 2 - 26 } & E & M & A & E & M & A & E & M & A & E & M & M \\
\hline Score & 5.47 & 5.33 & 5.37 & 4.97 & 4.93 & 4.77 & 4.30 & 3.63 & 3.37 & 3.17 & 2.70 & 1.33 \\
\hline Pain Level & severe & \multicolumn{3}{|c|}{ moderate } & \multicolumn{3}{|c|}{ moderate } & & mild & mild & mild-No \\
\hline
\end{tabular}

(E: evening, A: afternoon, M: morning)

Table 2: Difference in mean pain score of patients who did and did not take pain medication

\begin{tabular}{|l|c|c|c|}
\hline \multicolumn{1}{|c|}{ Day } & Took medication & Did not take medication & Pain level \\
\hline Day 1 & 6.15 & 4.81 & Severe \\
\hline Day 2 & 5.57 & 5.29 & Moderate \\
\hline Day 3 & 5.55 & 4.88 & Moderate \\
\hline
\end{tabular}

Table 3: Frequency of patients related to pain perception after placement of loop from day-I to day-7

\begin{tabular}{|l|l|c|c|c|c|c|c|}
\hline \multicolumn{2}{|c|}{ Questionnaire } & Day-1 & Day-2 & Day-3 & Day-4 & Day-5 & Day-7 \\
\hline 1 & Felt pain after placement of loop & 27 & - & - & - & - & - \\
\hline 2 & Felt immediate pain & 25 & - & - & - & - \\
\hline 3 & Pain was tolerable & 15 & 7 & 16 & 14 & 13 & 13 \\
\hline 4 & Pain while chewing or biting & 27 & 21 & 23 & 19 & 19 & 13 \\
\hline 5 & Pain level increased severely for 48 hours & 18 & 17 & 27 & 7 & 5 & 4 \\
\hline 6 & Pain interfered with daily activities & 19 & 15 & 12 & 0 & 0 & 0 \\
\hline
\end{tabular}


Table 4: Mean of peak pain (hours) with $95 \%$ Confidence Interval

\begin{tabular}{|c|c|c|c|c|c|}
\hline Day & $\begin{array}{l}\text { Patient } \\
\text { Number }\end{array}$ & $\begin{array}{l}\text { Uprighting } \\
\text { Spring } \\
\text { Loading Time }\end{array}$ & $\begin{array}{c}\text { Perceived Peak Pain in } \\
24 \text { Hours }\end{array}$ & $\begin{array}{l}\text { Peak pain difference in } \\
\text { hours }\end{array}$ & $\begin{array}{c}\text { Mean } \\
\text { Peak pain (hrs.) with 95\% } \\
\text { Confidence Interval }\end{array}$ \\
\hline \multirow{4}{*}{ Day-1 } & 1 & 10:00 am & 19:00 & 9:00 & \multirow{30}{*}{$\begin{array}{c}9: 40 \\
(9: 32-9: 51)\end{array}$} \\
\hline & 2 & $10: 30 \mathrm{am}$ & $20: 00$ & $9: 30$ & \\
\hline & 3 & 11:00 am & $20: 20$ & $9: 20$ & \\
\hline & 4 & $11: 30 \mathrm{am}$ & $21: 30$ & $10: 00$ & \\
\hline \multirow{4}{*}{ Day-2 } & 5 & 10:00 am & $19: 15$ & $9: 15$ & \\
\hline & 6 & $10: 30 \mathrm{am}$ & $19: 45$ & $9: 15$ & \\
\hline & 7 & $11: 00 \mathrm{am}$ & $20: 30$ & $9: 30$ & \\
\hline & 8 & $11: 30 \mathrm{am}$ & $21: 00$ & $9: 30$ & \\
\hline \multirow{4}{*}{ Day-3 } & 9 & 10:00 am & $19: 45$ & $9: 45$ & \\
\hline & 10 & $10: 30 \mathrm{am}$ & $20: 45$ & $10: 15$ & \\
\hline & 11 & $11: 00 \mathrm{am}$ & $18: 40$ & $7: 40$ & \\
\hline & 12 & $11: 30 \mathrm{am}$ & $19: 15$ & $7: 45$ & \\
\hline \multirow{4}{*}{ Day-4 } & 13 & 10:00 am & $19: 30$ & $9: 30$ & \\
\hline & 14 & $10: 30 \mathrm{am}$ & $20: 10$ & $9: 40$ & \\
\hline & 15 & $11: 00 \mathrm{am}$ & $20: 00$ & $9: 00$ & \\
\hline & 16 & $11: 30 \mathrm{am}$ & $20: 50$ & $9: 20$ & \\
\hline \multirow{4}{*}{ Day-5 } & 17 & 10:00 am & 18:45 & $8: 45$ & \\
\hline & 18 & $10: 30 \mathrm{am}$ & $19: 35$ & 9:05 & \\
\hline & 19 & 11:00 am & $20: 18$ & $9: 18$ & \\
\hline & 20 & $11: 30 \mathrm{am}$ & $20: 00$ & $8: 30$ & \\
\hline \multirow{4}{*}{ Day-6 } & 21 & $10: 00 \mathrm{am}$ & $19: 45$ & $9: 45$ & \\
\hline & 22 & $10: 30 \mathrm{am}$ & $20: 30$ & $10: 00$ & \\
\hline & 23 & $11: 00 \mathrm{am}$ & $19: 00$ & $8: 00$ & \\
\hline & 24 & $11: 30 \mathrm{am}$ & $21: 45$ & $10: 15$ & \\
\hline \multirow{4}{*}{ Day-7 } & 25 & 10:00 am & $20: 45$ & $10: 45$ & \\
\hline & 26 & $10: 30 \mathrm{am}$ & $20: 45$ & $10: 15$ & \\
\hline & 27 & 11:00 am & $19: 55$ & $8: 55$ & \\
\hline & 28 & $11: 30 \mathrm{am}$ & $21: 30$ & $10: 00$ & \\
\hline \multirow{2}{*}{ Day-8 } & 29 & 10:00 am & $20: 17$ & $10: 17$ & \\
\hline & 30 & $10: 30 \mathrm{am}$ & $20: 30$ & $10: 00$ & \\
\hline
\end{tabular}

\section{DISCUSSION}

A study by Ngan et al showed no significant difference in the level of discomfort of patients above 16 years of age in comparison to below 16 years. No significant difference in discomfort was noticed between the gender groups.?

Philipp et al noted that the level of discomfort increased continuously every hour after the insertion of either stainless steel or NiTi as first archwire with a peak discomfort during first night, remaining high on the second day and decreased thereafter to baseline level after seven days. No significant gender-specific differences were found in either archwire group. ${ }^{8}$ Sergl et al showed that an adaptation to pain and discomfort occurred during the first 3 to 5 days after placement of the appliance.? Ertan et al showed that in both groups; initial pain was perceived at 2 hours peaked at 24 hours and decreased by day-3. ${ }^{10}$
Fleminga et al revealed that the bracket type had no effect on subjective pain experience during the first week after initial placement of preadjusted orthodontic appliance." Scot et al found no evidence to suggest that Damon3 self-ligating brackets are associated with less discomfort than conventional pre-adjusted brackets during initial tooth alignment regardless of age or gender. ${ }^{12}$

Fernandes et al found that the level of discomfort increased continuously every hour after the insertion of stainless steel or NiTi archwire as first arch wires with a peak discomfort during the first night, remaining high on the second day and decreased therefore to baseline level after 7 days. ${ }^{13}$

Erdinc et al found the in both 0.014 and 0.016 inch archwire group initial pain was perceived at 2 hours, peaked at 24 hours and had decreased by day 3. ${ }^{14}$ Doll 
et al revealed that giving detailed information on any discomfort occurring and explaining how to reduce or eliminate it were vital factors in good treatment cooperation..$^{15}$ Mandall et al states that there were no statistically significant differences between archwire sequences for patient discomfort. ${ }^{16}$

Polat et al concluded that acetaminophen is the analgesic of choice for the relief of orthodontic discomfort. In their study, acetaminophen relieved orthodontic pain in a manner similar to other efficient analgesics and can be preferred as the analgesic of choice because of its minor adverse effects. ${ }^{17}$

Bergius et al suggested that orthodontic treatment may cause some degree of suffering for the patients, it is important for orthodontists to handle this situation in the best possible way. Some ideas about the possibilities of avoiding, reducing or alleviating pain in orthodontics are discussed. ${ }^{18}$
Bernhardt et al states ibuprofen taken 60 minutes before separator placement alleviates pain at 2 hours and at bedtime after treatment. ${ }^{19}$ Bondemark et al concluded separation effect of the two separators was considered clinically equivalent and since pain of moderate intensity occurs during the separation period, analgesics and soft food can be recommended. ${ }^{20}$

The present study reports similar finding related to pain. Peak pain level after the placement of molar uprighting spring was observed on first night till the next morning, which gradually decreased from next day with a residual mild pain on fourth to fifth day. Pain almost disappeared on day-7.

\section{CONCLUSION}

Peak pain level was observed on day-1. Pain was at its highest peak on day-1 during the evening at 9:40 pm. Pain was strongly associated with intake of pain medication on day-1 with gradual decrease over a period of a week.

\section{OJN}

\section{REFERENCES}

1. Lobre WD, Dunn WJ. Pain control in orthodontics using vibration. Research Highlight, 2016; 3:e1165. doi:10.14800/ip.11.

2. Kausal S, Agrawal A, Soni UN, TosshniwalNG, Misal A. Pain and discomfort during Oorthodontictreatment. Ind J OrthodDentofac Res 2015; $1(1): 5-10$.

3. Rakhshan H, Rakhshan V. Pain and discomfort perceived during the initial stage of active fixed orthodontic treatment. Saudi Dent J, 2015; 27(2):81-7.

4. Abdelrahman RS, Al-Nimri KS, Al Maaitah EF. Pain experience during initial alignment with three types of nickel-titanium archwires: A prospective clinical trial. Angle Orthod 2015; 85(6):1021-6.

5. Woodhouse NR, Andrew TD, Papageorgiou SN,, Johnson N, Slipper C, Grant J, Maryam A, Cobourne MT. Supplemental vibrational force does not reduce pain experience during initial alignment with fixed orthodontic appliances: A multicenter randomized clinical trial. 2015: Scientific Reports.

6. Krishnan V.Orthodontic pain: From cause to management-A review. Eur J Orthod 2007; 29, $170-9$.

7. Ngan P, Kess B, Wilson S. Perception of discomfort by patients undergoing orthodontic treatment. Am J Orthod Dentofac Orthop. 1989; 96:47-53.

8. Scheurer PA, Firestone AR, Br-rrgin WB. Perception of pain as a result of orthodontic trcatment with fixed appliances. Eur J Orthod, 1996; 18:349-57.

9. Klages U, Zentner A. Pain and discomfort during orthodontic treatment: Causative factors and effects on compliance. Am J Orthod Dentofacial Orthop. 1998; 114(6):684-91.

10. Asham AA, Southard KA. Orthodontic pain. Am J Orthod Dentofacial Orthop, 2004; 125:18A.

11. Fleminga PS, DiBiaseb, AT, Sarric G, Leed RT. Pain experience during initial alignment with a self-ligating and a conventional fixed orthodontic appliance system: A randomized controlled clinical trial. Eur J Orthodontics. 2007; 29:170-9.

12. Scott P, Sherriff M, DiBiase, AT, \& Cobourne MT. Perception of discomfort during initial orthodontic tooth alignment using a self-ligating or conventional bracket system: Randomized clinical trial. Eur J Orthod, 2008; 30(3):227-32.

13. Fernandes LM, Ogaard B, Skoglund L. Pain and discomfort experienced after placement of a conventional or super elastic Niti aligning archwire. A randomized clinical trial. J Orofac Orthop. 1998; 59:331-9.

14. Erdinc AME, Dincer B. Perception of pain during orthodontictreatment with fixed appliances. Eur J Orthod. 2004; 26:79-85.

15. Doll GM, Zentner A, Klages U, Sergl IJG. Relationship between patient discomfort appliance acceptance and compliance in orthodontic therapy. J Orofac Pain Orthop. 2000; 61, 398-413.

16. Mandall NA, Lowe Cl, Worrhington HV, Sandler J, Denvent S, Abdi-Oskovei. M. Which orthodontic archwire sequence? A randomized clinical trial. Eur J Orthod.2006; 28:561-6.

17. Polat O, Karaman Al. Pain control during fixed orthodontic appliance therapy. Angle Orthod. 2005; 75:214.

18. Bergius M, Kiliardis S, Berggren U. Pain in orthodontics: A review and discussion of the literature. J Orofac Orthop. 2000; 61:125-37.

19. Bernhardt MK, Southard KA, Batterson KD, Logan HL, Baker KA, Jakobsen JR. The effect of preemptive and/or postoperative ibuprofen therapy for orthodontic pain. Am J Orthod Dentofac Orthop. 2001; 120(1):20-7.

20. Bondemark L, Fredriksson K, Iros S. Separation effect and perception of pain and discomfort from two types of orthodontic separators. Wor J Orthod 2004; 5:172-6. 